\section{Nanoscale Thermal Property \\ Characterization of Automotive Polymer Coatings}

Louis T. Germinario

Eastman Chemical Company, Corporate Analytical Services,

Kingsport, TN

germ@eastman.com

\section{ABSTRACT}

This article discusses AFM-based localized thermal analysis of crosslinked polymer coatings based on a recent breakthrough in nanoscale thermal probe technology. Examples include the monitoring of the softening point of automotive clearcoat systems, as a function of cure time and cure temperature and characterization of degradation and embrittlement of weathered acrylic-polyurethane coatings. Comparison of nano thermal analysis with bulk DSC and MDSC is made and its inherent advantages over DSC in analyzing surfaces is demonstrated.

\section{INTRODUCTION}

Organic polymeric materials are widely used as coatings in a variety of markets and applications, primarily to improve surface properties, appearance and performance. These applications are becoming more sophisticated, and due to the multivariate nature of coatings, their decreased dimensions often produce layers of polymers having different properties. In addition, the viscoelastic nature of most polymers leads to a marked time and temperature dependence on performance [1].

Chemically crosslinked coatings have evolved as the materials of choice and are commonly employed as automotive clearcoats to protect against environmental influences and provide scratch, mar and chip resistance, as well as corrosion and solvent resistance, while still maintaining a high gloss and appearance [2]. The addition of chemical additives to improve photostability, coupled with variable crosslinking reactions, often produce heterogeneities ranging in size from nanometers to microns that are more susceptible to degradation $[3,4]$. The Atomic Force Microscope (AFM) has proven to be invaluable for not only imaging polymeric systems [5], but for probing tip/sample interactions, (as in phase imaging) for mapping mechanical (elasticity, hardness, etc) and chemical properties [6,7].

Recent breakthroughs have enabled the fabrication of thermal probes with end radius of $\sim 20 \mathrm{~nm}$ [8] which enable the AFM to probe local thermal properties at a sub-100nm size scale. This article covers the preliminary work done at Eastman Chemical on the application of sub-100nm thermal analysis on crosslinked polymer coatings. Examples include the monitoring of the softening point of automotive clearcoat systems, as a function of cure time and cure temperature and characterization of degradation and embrittlement of weathered acrylic-polyurethane coatings. Comparison of nano thermal analysis with bulk DSC (Differential Scanning Calorimetry) and MDSC (Modulated DSC) is also discussed.

\section{EXPERIMENTAL}

Experiments were performed using a Veeco Dimension 3000 AFM equipped with an Anasys Instruments (AI) nano-TA module and AI nanoscale thermal probes. The flow of current through the cantilever results in heat generation at the highly resistive heater region, while little heating occurs in the highly conductive legs. Each probe is calibrated by using it to identify the onset of known sharp melting points of various polymer standards (polycaprolactone, high density polyethylene and polyethylene-terephthalate).. The heating rate used for this analysis was $2{ }^{\circ} \mathrm{C} / \mathrm{s}$ (though the nano-TA allows the probe heating rate to be controllably varied up to 600,000 ${ }^{\circ} \mathrm{C} / \mathrm{s}$ ) . All images were recorded using tapping mode AFM.

Sample surfaces are first scanned at ambient temperature to generate an image that is used to localize and define features of interest. The probe is next moved to select areas or features and the temperature of the stationary tip is then ramped linearly with time. This mode of analysis is referred to as local thermal analysis (LTA). As the probe is heated, the tip typically shows an increase in deflection due to local thermal expansion of the material beneath the tip (Figure 1B). As the thermal transition is reached (glass transi-
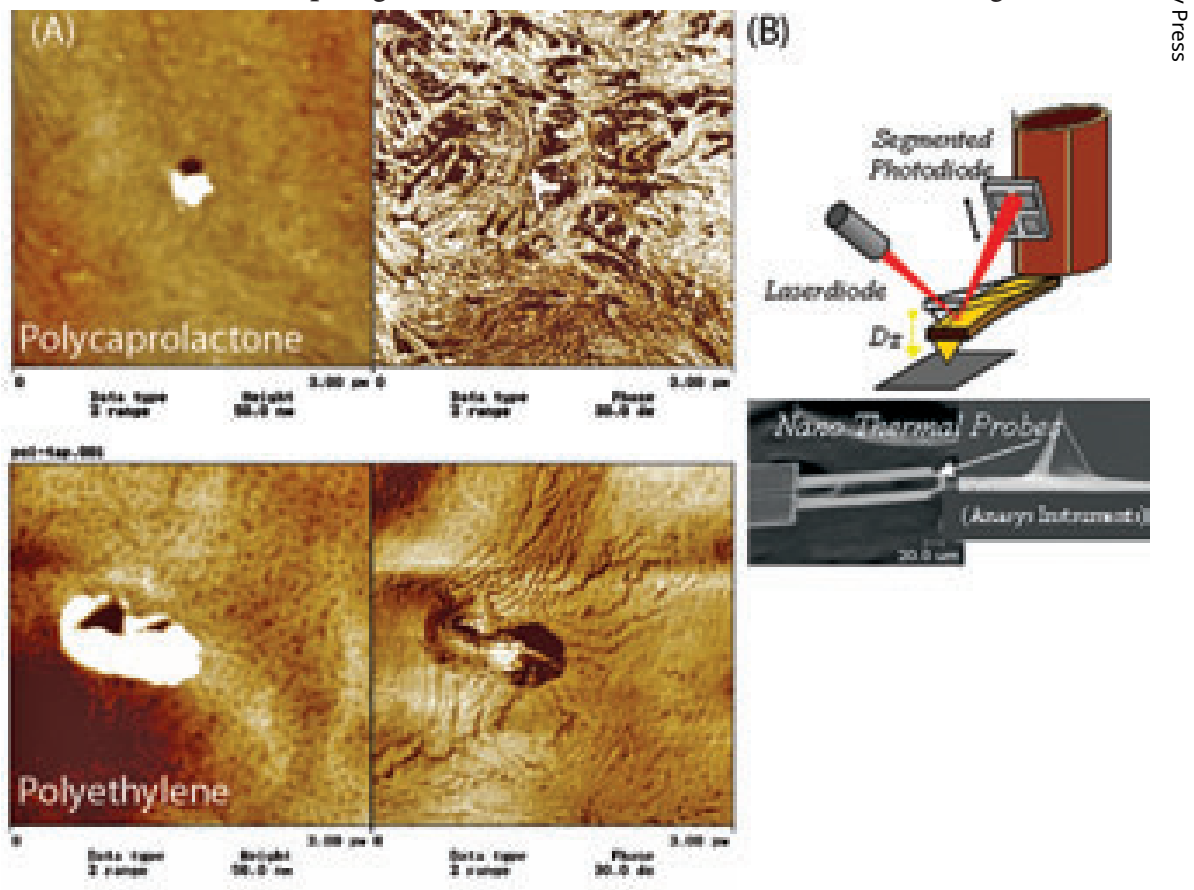

Figure 1. Example of test polymer film samples (polycaprolactone and polyethylene) used for calibration of nanothermal probes. (A) Height (left) and phase (right) images provide evidence of crystalline lamellar structure and spatial resolution comparable to standard AFM probes. Nano thermal probes (C) mount directly onto the Dimension head (B).

tion temperature $(\mathrm{Tg})$, softening point or crystalline melting point $(\mathrm{Tm})$ ), the material softens beneath the tip and the probe forms an indentation as it penetrates the sample (figure 1A). This provides the nanoscale equivalent of a bulk thermo-mechanical analysis experiment. In order to confirm the tested points of interest, images are routinely recorded after performing the temperature ramp.

The resonance frequency of the thermal probes (fig. 1C) used in this study is typically $\sim 20 \mathrm{kHz}$, while the drive frequency needed to drive the oscillation of tips is $\sim 20$ volts. These conditions produce very low RMS amplitudes ( 1.0 to 0.4 volts). Imaging is accomplished by enabling the $Z$ modulation function, which result in height and phase images with sufficiently high spatial resolution to resolve 


\section{OLYMPUS}

Your Vision, Our Future

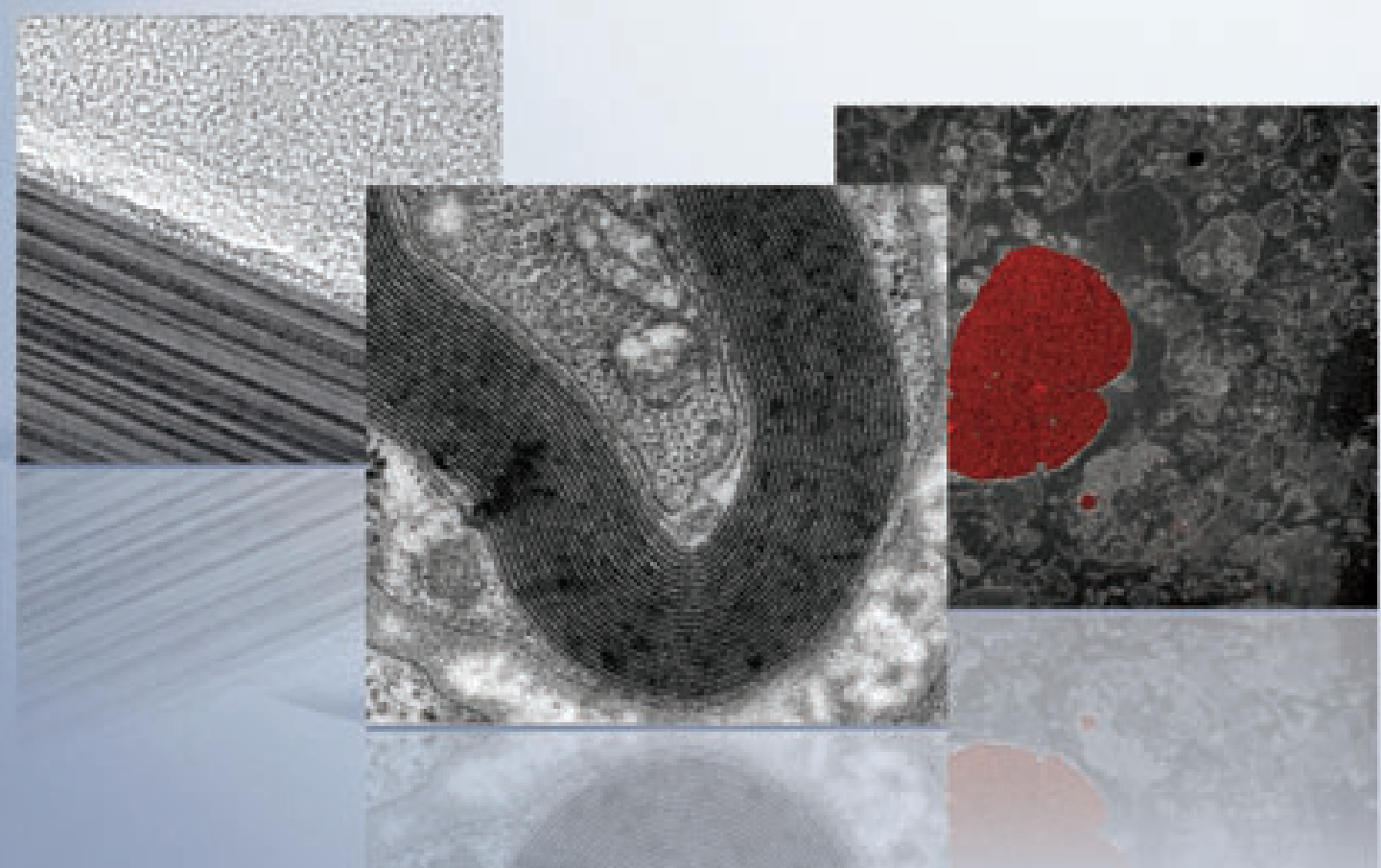

\section{ELECTRON MICROSCOPY MADE SIMPLE} CANTEGAG2

\section{$2 \mathrm{k} \times 2 \mathrm{k}$ ON-AXIS TEM CAMERA}

The Cantega ${ }^{\mathrm{G} 2}$ is the 2 nd generation Olympus Soft Imaging Solutions $2 \mathrm{k} \times 2 \mathrm{k}$, bottom-mounted CCD TEM camera. And it's for all TEM brands. This fiber-optically coupled camera sets new image benchmarks regarding resolution, uniformity and sensitivity for bottom-mounted TEM cameras by using an optimized YAG scintillator as the default.

The Cantega ${ }^{\mathrm{G} 2}$ offers $14 \mu \mathrm{m}$ pixel size, a dynamic range of 14 bits, various exposure times, two read-out modes and frame ratesup to $6 \mathrm{fps}$. Details of your materials science or life science samples can now be captured due to the Peltier-cooling down to $-10^{\circ} \mathrm{C}$ and the optimal signal-to-noise ratio of Cantega ${ }^{\mathrm{G} 2}$. Obtaining this level of detail used to be mere guesswork.

In conjunction with iTEM - our universal TEM imaging platform - users have everything necessary for applications requiring high sensitivity and low noise like electron tomography, diffraction, electron-energy filtering, immunogold and particle analysis, tele-microscopy, archiving and reporting.

Cantega ${ }^{\mathrm{G} 2}-2 \mathrm{k} \times 2 \mathrm{k}$ TEM Camera

For detailed information please contact:

Olympus Soft Imaging Solutions

info.osis@olympus-sis.com

www.soft-imaging.net

North America: (888) FIND SIS, +1 (303) 234-9270

Europe: +49 (251) 79800-0

Asia / Pacific: +60 (3) 8313-1400

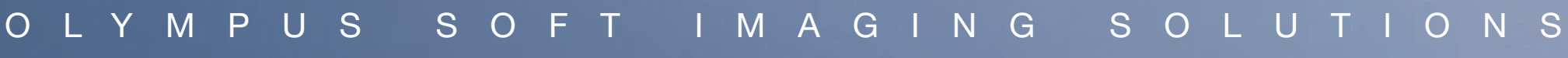




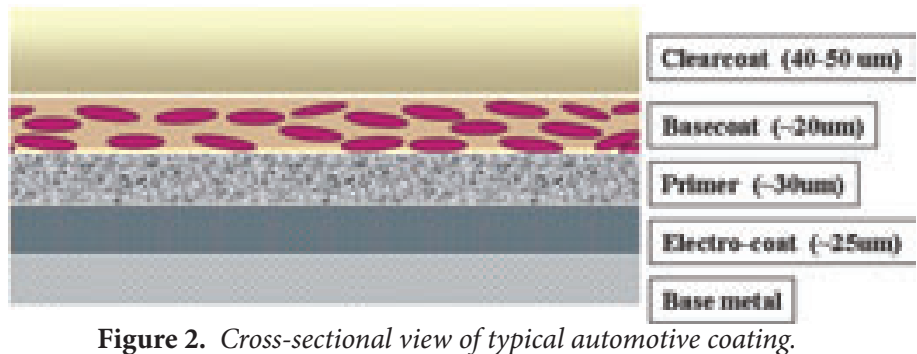

polymer lamellar structures. Height images (fig. 1A) often show the presence of mounds of material associated with indentations. This deposit is most likely polymeric material that collects and solidifies around the tip after performing a local thermal analysis. This process of imaging regions after performing local thermal analysis was found to be a useful for both examining the condition of the probe and for cleaning probes.

\section{MATERIALS}

Two types of coatings were studied, (A) commercial acrylic polyol crosslinked with diisocyanate resin, catalyzed with dibutyl-tin-di-laurate (DBTDL) and cured 30 minutes at $60 \mathrm{C}$; and (B) weathered acrylic-polyurethane (AU) coatings. The weathered AU coatings consist of styrene-acrylic polymer crosslinked with polymeric 1, 6 hexamethylene diisocyanate and containing two types of $\mathrm{TiO}_{2}$ particles, Degussa P25 (average particle size $\approx 20 \mathrm{~nm}$; uncoated and high photoactivity) and $\mathrm{R} 9$ (average particle size $\approx$ $250 \mathrm{~nm}$; coated with $\mathrm{Al}_{2} \mathrm{O}_{3}$ (6\%).

\section{RESULTS AND DISCUSSION}

A cross-sectional view of a typical commercial automotive coating (figure 2.) shows the complex, multi-functional nature of these coating systems. Due to the fact that the clearcoat is the first line of defense against environmental influences, understanding surface, near-surface chemical and mechanical property development as a function of composition, cure time and environmental exposure is fundamental to improving their performance. Furthermore, the increased demand for low VOC systems in the automotive refinishing industry places greater demands for attaining fast cure at ambient temperature in order to reduce the investment in drying equipment and the time of repair.

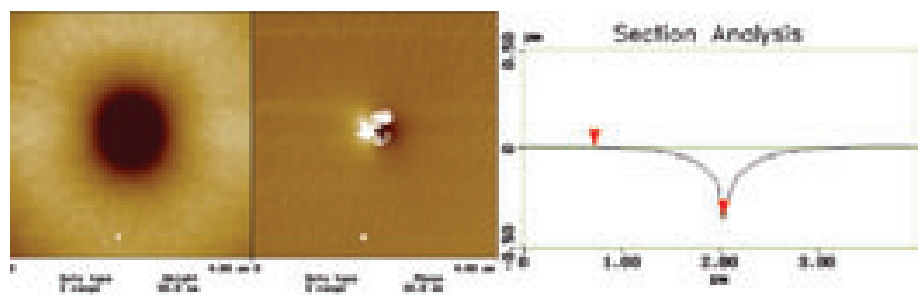

Figure 3. Indentation produced by the thermal probe after measurement of softening point of an acrylic clearcoat film.

\section{PROBE IMAGING AND THERMAL CHARACTERISTICS}

Fig 1. shows the ambient temperature tapping mode images of polyethylene and polycaprolactone films with the thermal probes and the resolution is clearly comparable to regular non-thermal AFM probes. The thermal response of the probes was next investigated using acrylic-urethane coatings. Coatings that were a few weeks old were tested by LTA in order to measure the coating's response to a thermal scan and determine the indentation morphology and depth.
A topview (Fig 3.) of the acrylic coating after LTA testing shows the formation of a residual indent $\sim 350 \mathrm{~nm}$ deep. The measured indentation depth provides an estimation of the sampling depth using LTA analysis and can serve as a basis for comparison of softening points $(\mathrm{Tg})$ from the same coatings with bulk film measurements by MDSC.

The dependence of the glass transition temperature on heating and cooling rates is well known and shown to be a kinetic effect that is due to a temperature dependence of structural relaxation

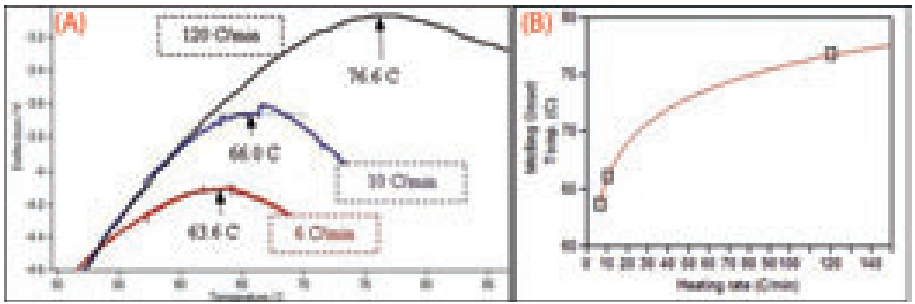

Figure 4. Dependence of (acrylic) film softening point on tip heating rate (A). In particular, softening point onset temperature shows a linear dependence on the logarithm of the tip heating rate (B).

rates. This temperature dependence also influences the shape of the heat capacity $\left(C_{p}\right)$ near the Tg. [9]. In particular, experimental measurements showed $\mathrm{Tg}$ to depend linearly with the logarithm of the heating rate. In order to test the ability of LTA to measure a heating rate dependence of softening temperature using thermal probes, experiments were conducted on acrylic clearcoat films (figure 4A). The three scan rates tested, $(6,10$ and $120 \mathrm{C} / \mathrm{min})$ by LTA clearly show an increase in softening temperature with increased heating rates and a linear logarithmic rate dependence $($ RSquare $=0.999)$, similar to that shown by the bulk DSC measurement (figure 5B).

We next explore use of LTA for measuring cure rates from softening temperature. A coating's softening point is a good measure of crosslink density [10]. The formation of three-dimensional networks due to chemical reactions is widely accepted as a means of improving a coating's properties. It has been shown on a variety of clearcoat systems $(1 \mathrm{~K}$ and $2 \mathrm{~K}$ solvent-borne clearcoat, and $1 \mathrm{~K}$ and $2 \mathrm{~K}$ waterborne clearcoat) cured at different times, at different temperatures, all displayed an increase in $\mathrm{Tg}$, with increasing cross-
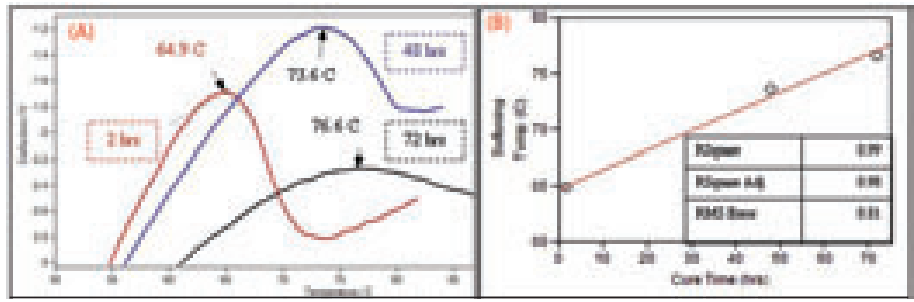

Figure 5. Effect of curing time at ambient temperature of acrylic clearcoat on softening temperature $(A)$. The softening temperature displays a linear relationship over the cure times measured (B).

link density [11]. In addition, mechanical properties of coatings also depend on the extent of crosslinks as expressed by the inverse relationship between molecular weight between crosslinks $\left(M_{x}\right)$ and tensile storage modulus $\left(E^{\prime}\right)[1]$.

In order to test the utility of LTA for measuring cure rates, softening points of commercial acrylic coatings cured for 30 minutes at $60 \mathrm{C}$, were tested from $2 \mathrm{hrs}$ to $72 \mathrm{hrs}$, after the $30 \mathrm{~min}$. cure at 60 C. Figure 5 shows a gradual increase in measured softening temperature with time. A plot of cure time versus softening temperature shows a linear relationship over the cure times measured. 

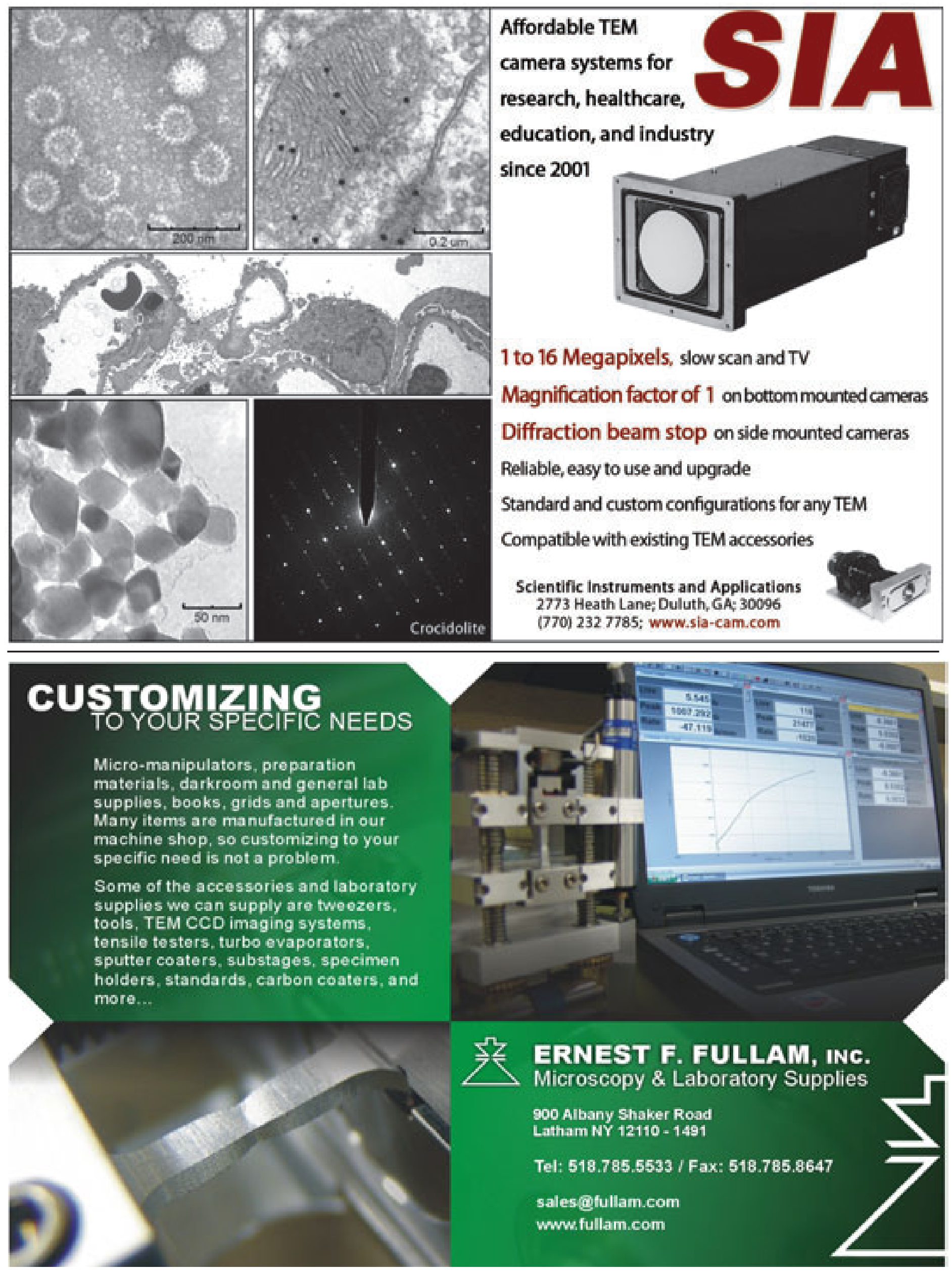


\begin{tabular}{|c|c|c|c|c|}
\hline & Aerylie Control & Acrylie + A & Aendile $B$ & Acndle $B+A$ \\
\hline Tetend: (PA hing) & (79) & 601 & 60 & 40 \\
\hline \multirow{2}{*}{$\begin{array}{l}\text { Fane- Themal AFM: } \\
\text { Onset Sohening Teeop. C. }\end{array}$} & IIII & था? & and & E.S \\
\hline & (1) & S201 & a.82 & A.M \\
\hline Avg & 579 & जूडs & a.7 & 6.0 \\
\hline Sid Der. & 0.27 & au & a.et & a.15 \\
\hline \multicolumn{5}{|l|}{ Tetend: (45 hra) } \\
\hline \multirow{3}{*}{$\begin{array}{l}\text { Wane-Thomal Afur: } \\
\text { Oneet Sohening Temp. C. }\end{array}$} & 6.30 & [था & $n$ & 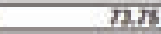 \\
\hline & 0.80 & QW & 7.14 & 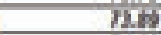 \\
\hline & 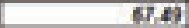 & 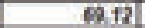 & n.m. & 720 \\
\hline Avg & ज.217 & करेखण & II2 & 720 \\
\hline sid Der. & $a x$ & $a+19$ & 0.24 & a.14 \\
\hline
\end{tabular}

Nano-Thermal Analys of Clearcoat Formulations

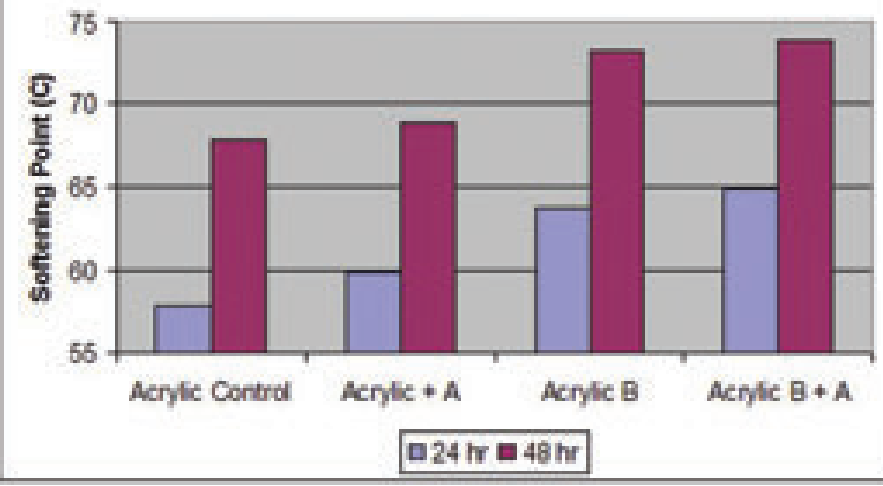

Increase in softening temperatures as a function of time, 24 and 48 hrs, for select acrylic coatings (A). Bar plot (B).

\section{(A)}

\section{Effect of Weathering on Softening Temperature of Surfaces of Acrylic-Urethane Polymer} (NanoThemalaft)

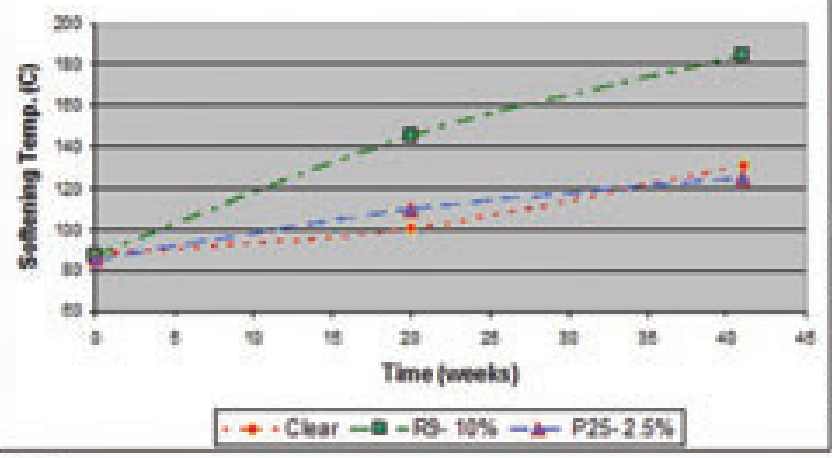

\section{(B)}

Effect of Weathering on Softening Temperature of Acrylic-Urethane Polymer Matrix

(uosc ist Scan a SC/min)
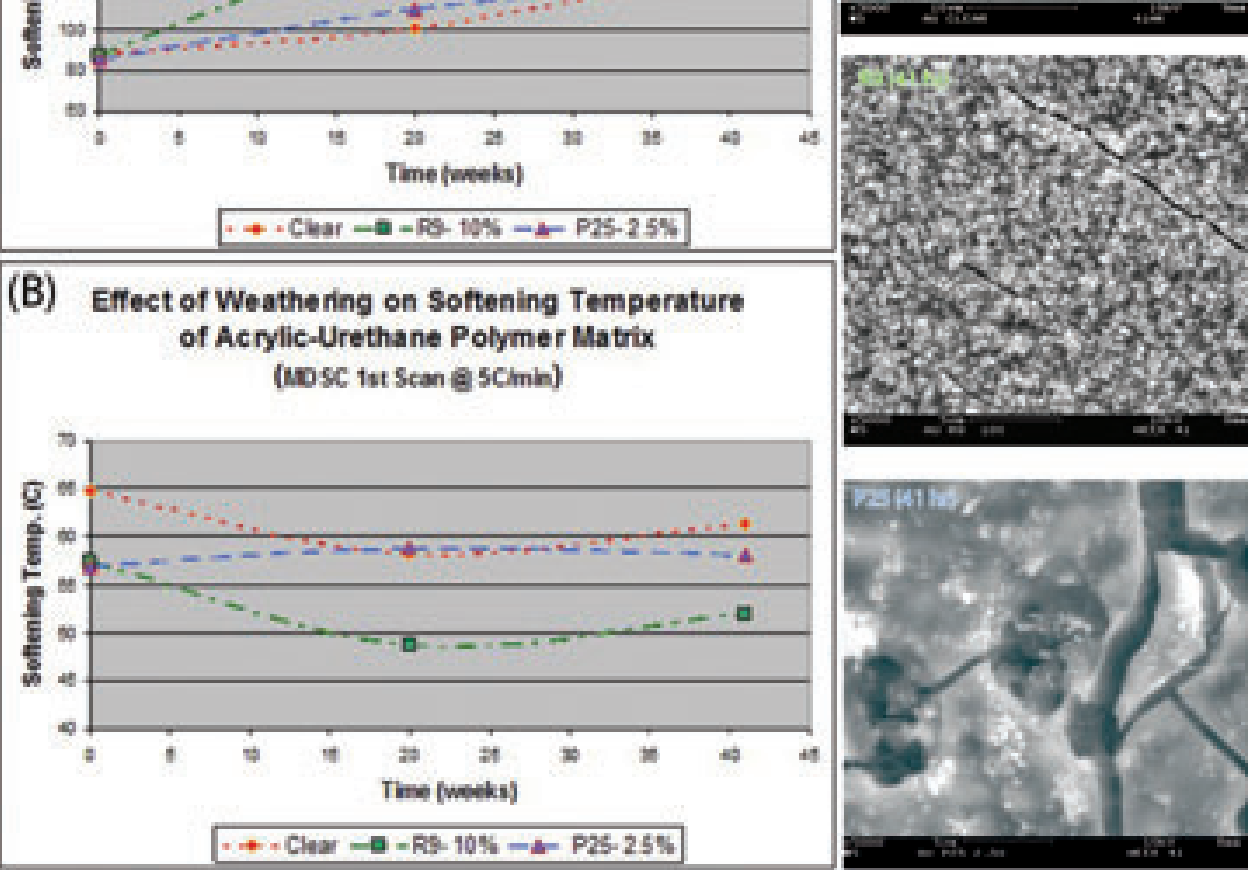

Figure 6. Comparison of softening temperatures measured for UV-exposed (0,20 and $41 \mathrm{wk})$ clear and $\mathrm{TiO} 2$ filled (P25 and R9) acrylic urethane coatings using nano thermal analysis (A) and MDSC (B). Surface morphology was also analyzed by scanning electron microscopy.
We next proceeded to use LTA to follow the increase in softening temperature (and crosslink density) as a function of time, 24 and $48 \mathrm{hrs}$, for select acrylic coatings after their 30 minute bake at $60 \mathrm{C}$ (table 1). Pooling of the measured standard deviations of softening points, made in triplicate, from eight coating systems provided a good measure of the LTA test reproducibility. The calculated standard deviation for these coatings is $0.26 \mathrm{C}$ (Table 1A).

Photo-degraded Acrylic-polyurethane (AU)coatings: These coatings were exposed, 20 weeks and 41 weeks to UV-A and UV-B. They consist of styrene-acrylic polymer crosslinked with 1, 6 hexamethylene diisocyanate and contain two types of $\mathrm{TiO}_{2}$ particles, Degussa P25 (average particle size $\approx 20 \mathrm{~nm}$; uncoated and highly photoactive) and R9 (average particle size $\approx 250 \mathrm{~nm}$; coated with $\mathrm{Al}_{2} \mathrm{O}_{3}(6 \%)$. Figure 7 summarizes and compares softening temperatures measured by LTA (figure 6A), in comparison with $\mathrm{Tg}$ from MDSC, (figure 6B).

These data clearly show the surface sensitivity of LTA, as compared to the bulk Tg measurement using MDSC. A considerable body of knowledge has accumulated on the surface sensitivity of photodegradation processes [12]. It is therefore not surprising that NTA provides a sensitive measure of photo-oxidative effects of UV exposure for clear and $\mathrm{TiO}_{2}$-filled coatings and displays an increase in softening temperature (i.e. crosslink density) with increased UV exposure times. In comparison, the MDSC characterization of the bulk thin film is not capable of differentiating surface effects from bulk and cannot detect the surface chemi$\mathrm{cal}$ and structural degradation suffered by coatings as shown by the scanning electron micrographs from 41 week exposed coatings (figure 6).

\section{ACKNOWLEDGEMENTS}

The author expresses his gratitude to Drs. Aaron Forster and Stephanie Watson (NIST) for valuable discussions and the supply of weathered, acrylic-polyurethane coatings. We also thank Dr. Deepanjan Bhattacharya and Mr. Chip Williams for the supply of acrylic clearcoats.

\section{REFERENCES}

1. L. C. E. Struik, Physical Aging of Amorphous Polymer and other Materials, Elsevier, Amsterdam, 1978.

2. E. V. Schmidt, Exterior Durability of Organic Coatings. FMJ Intern. Publ., Redhill Surrex, 1988.

3. H. Corti et al, Prog. Org. Coat. 1982, 10,5.

4. C. L. Wu et al, Prog. Org. Coat. 1995, 25, 379.

5. S. N. Magonov et al, Surf. Sci. 1997, 375, L385.

6. S. N. Magonov et al, Surf. Sci. 1997, 389, 201.

7. G. Haugstad and R. R. Jones, Ultramicroscopy, $1999,76,77$.

8. W.P. King et al, "Atomic Force Microscope Cantilevers for Combined Thermomechanical Data Writing and Reading," Applied Physics Letters 78, pp. 1300-1302, 2001.

9. G. S. Grest and M. H. Cohen, Phys. Rev. B. 1980, $21,4113$.

10. D. J. Skrovanek and C. K. Schoff, Prog. Org. Coat. $1988,16,135$.

11. W. Schlesing et al, Prog. Org. Coat. 2004, 49, 197

12. D. R. Fagerburg, "Weathering of Polyester and Copolyester Sheeting," tlas School of Natural and Accelerated Weathering, Miami, FL; April 28, 1999. 


\section{थ COLLEGE OF MICROSCOPY www.collegeofmicroscopy.com}

\section{IACET I LEARN FROM EXPERIENCE ...}

\section{LEARN FROM THE EXPERTS}

The College of Microscopy offers a variety of courses in light microscopy, electron microscopy, infrared and Raman spectroscopy, sample preparation, and small particle handling. The courses provide students with a maximum of hands-on experience using light and electron microscopes, learning sample preparation and micromanipulation techniques. The College of Microscopy's 40,000 sq. ft. teaching facility offers state-of-the-art microscopy equipment, modern classrooms and labs, a 140 seat auditorium, and many other amenities.

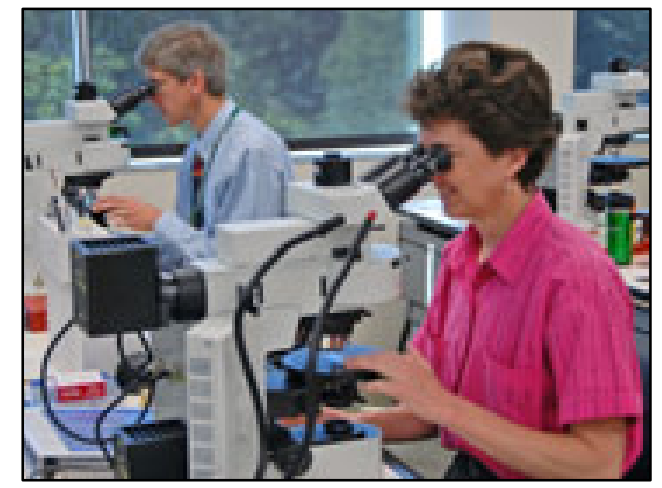

\section{COURSE SCHEDULE}

(Please check www.collegeofmicroscopy.com for an updated list of courses.)

\section{Polarized Light Microscopy}

COM100: Modern Polarized Light and Chemical Microscopy April 28 - May 2, 2008

June 16 - 20, 2008

September 8 - 12, 2008

COM160: Techniques of Optical Crystallography

July $14-18,2008$

\section{Electron Microscopy}

COM200: Scanning Electron Microscopy

March 31 - April 4, 2008

October 6 - 10, 2008

COM250: Transmission Electron Microscopy

March 25 - 27, 2008

September 16 - 18, 2008

\section{Sample Preparation}

COM300: Microscopic Particle Handling: Particle Isolation, Manipulation, and Mounting

October 6 - 10, 2008

COM310: Sample Preparation: Pharmaceutical and Medical Devices

March $12-13,2008$

COM311: Sample Preparation: Polymers, Paint, and Coatings

February 6 - 7, 2008

COM312: Sample Preparation: Forensic Trace Evidence April $23-24,2008$

\section{Biological/Medical}

COM700: Body Fluid Identification and Microscopic Methods of Sperm Detection for Forensic DNA/Serology/Biology December 11-13, 2007

\section{Special Applications}

COM400: Microscopical Examination of Forensic Trace Evidence (Part 1)

June 16 - 20, 2008

COM410: Microscopical Identification of Pharmaceutical Materials and Contaminants

March 31 - April 4, 2008

COM415: USP \{788\} Particulate Matter in Injections April 10, 2008

COM420: Microscopical Identification of Pigments for Art Conservation and Architectural Restoration Professionals September 15 - 20, 2008

COM425: Introduction to the Microscopical Identification of Conservation Materials

June $9-13,2008$

COM430: Microscopical Identification of White-Powder Unknowns

February $11-15,2008$

October 6 - 10, 2008

\section{Imaging/Software}

COM500: Image Analysis Workshop

September 16 - 18, 2008

COM520: PAX-it Image Database and Image Analysis Workshop

February 27 - 28, 2008

\section{Spectroscopy}

COM600: Infrared Microscopy

April 29 - May 1, 2008

November 4 -6, 2008

COM610: Raman Microscopy

October 7 - 9, 2008 